УДК 655.3.022.1

\title{
АЛГОРИТМ ОБ'ЄКТИВНОГО ЦИФРОВОГО ВИЗНАЧЕННЯ ПАРАМЕТРІВ СУМІЩЕННЯ ФАРБ У АРКУШЕПЕРЕДАВАЛЬНИХ СИСТЕМАХ
}

๑ В. Ф. Морфлюк д.т.н., професор, І. С. Карпенко, аспірантка, НТУУ «КПІ», Київ, Україна

В статье разработан алгоритм объективного цифрового определения параметров совмещения красок в листопередающих системах печатных машин на основании использования цифровых средств обработки импульсных сигналов, что обеспечивает необходимую точность контроля и стабилизации продольного, поперечного и диагонального совмещения красок в реальном масштабе времени.

In this article is developed the algorithm of objective digital definition of parameters colors registers in sheet transfer systems of sheet-fed presses on the basis of the use of digital processing of pulsed signals, which provides the necessary accuracy of control and stabilization of the longitudinal, transverse and diagonal color register in real time.

\section{Постановка проблеми}

Важливим показником якості друкованої продукції $€$ точність суміщення фарб друкарських відбитків на кожній секції багатофарбової друкарської машини. У сучасних аркушевих машинах суміщення фарб не повинно перевищувати 0,01-0,05 мм [1, 2]. Така точність при високій швидкості транспортування аркуша ставить перед аркушепередавальною системою підвищені вимоги.

Однією з основних задач аркушепередавальної системи друкарської машини є визначення та стабілізація параметрів поперечного, поздовжнього та діагонального суміщення фарб, що забезпечує якісний друк. Поперечне суміщення полягає у розбіжності накладання фарб перпендикулярно руху аркуша, поздовжнє суміщення фарб характеризується у напрямку руху аркуша, діагональне суміщення фарб, що визначається під певним кутом друку.

Тому актуальним є дослідження процесу об'єктивного цифрового визначення параметрів суміщення фарб у аркушепередавальних системах для подальшого визначення напрямку прогнозованої стабілізації суміщення фарб, з метою забезпечення відповідної якості друкованої продукції у реальному масштабі часу.

\section{Аналіз попередніх} досліджень

У аркушевих друкарських машин проблема суміщення фарб вирішується приведенням формного циліндру безпосередньо перед друком тиражу $[3,4]$. Процес контролю поперечного, поздовжнього та діагонального суміщення фарб виконується у більшості машин шля- 
хом друку пробного відбитка за допомогою аналізу технологічних міток, а його стабілізація виконується механізмами осьового, колового та діагонального приведення на початку друку. Осьове приведення полягає в переміщенні формного циліндра вздовж його вісі, колове приведення виконується поворотом формного циліндра відносно його вісі обертання, діагональне приведення виконується кутовим переміщенням вісі формного циліндра відносно однієї опори чи зміщення заднього краю форми в осьовому напрямку. При виявленні дефектів суміщення фарб під час друку тиражу дана проблема вирішується тільки повною зупинкою друкарської машини.

У аркушевих друкарських машинах, які забезпечені засобами автоматизації приведення фарб на основі принципів аналогового керування [1, 2], визначається значним часом для обробки та аналізу сигналів з датчиків на кожній друкарській секції.

Задача автоматизації процесу суміщення фарб на аркушевих друкарських машинах обумовлює проблему дослідження та удосконалення підсистем визначення та стабілізації суміщення фарб в аркушепередавальних системах на основі сучасних програмно-апаратних засобів керування з використанням об'єктивних цифрових засобів визначення параметрів суміщення фарб у реальному масштабі часу.

\section{Мета роботи}

Метою статті $є$ розробка алгоритму визначення параметрів суміщення фарб у аркушепере- давальній системі на основі цифрової обробки параметрів імпульсних сигналів для забезпечення визначеної точності контролю та стабілізації в реальному масштабі часу.

\section{Результати проведеного дослідження}

Алгоритм функціонування цифрової підсистеми визначення параметрів суміщення фарб у аркушепередавальній системі складається з трьох етапів. Перший етап полягає у формуванні імпульсних сигналів при скануванні правої та лівої технологічних міток у вигляді прямокутних трикутників, які друкуються на першій друкарській секції машини по обидві сторони аркуша. Перед кожною друкарською секцією, починаючи з другої, після ідентифікації аркуша оптичним датчиком синхронізації, на вхід аналого-цифрових перетворювачів правої та лівої технологічних міток (АЦПП, АЦПЛ) подається аналогові сигнали з оптичних датчиків, які пропорційні освітленню міток та за їх межами на аркуші паперу. На виходах АЦПП та АЦПЛ у просторі формується цифровий масив значень амплітуди перетворених сигналів у відповідний момент часу. Часова діаграма для визначення параметрів суміщення фарб для кожної з міток представлена на рис. 1 [5].

Другий етап функціонування полягає у визначенні часових характеристик імпульсних сигналів для лівої ( $\left.\tau_{\text {вимір.л }}, \tau_{\text {імп.л }}\right)$ та правої міток $\left(\tau_{\text {вимір.п, }}, \tau_{\text {імп.п }}\right)$, що базується на статистичному методі визначення амплітуд імпульсного сигналу для кожної 


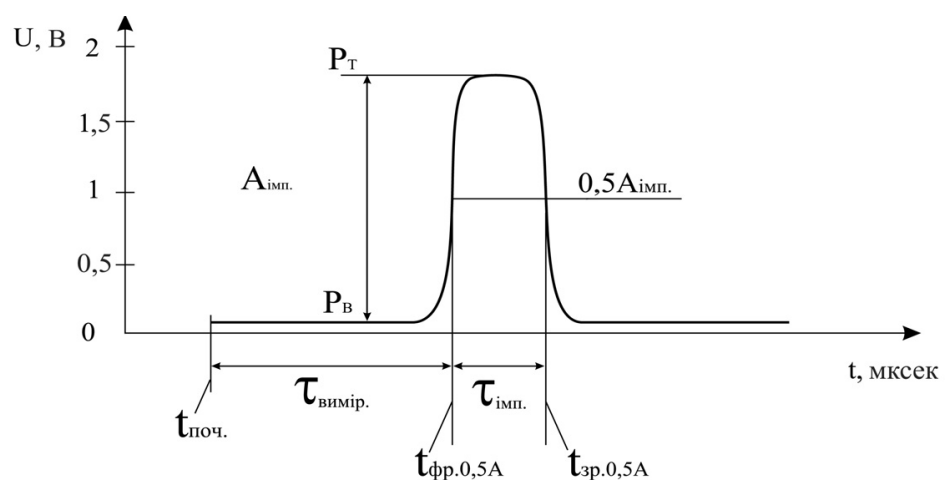

Рис. 1. Часова діаграма для визначення параметрів суміщення фарб у аркушепередавальних системах: $\mathrm{A}_{\text {iмп }}$ - амплітуда імпульсного сигналу; $\tau_{\text {вимір }}-$ час від початку синхросигналу до появи імпульсу; $\tau_{\text {імп }}-$ тривалість імпульсного сигналу; $\mathrm{t}_{\text {поч }}-$ час початку; $\mathrm{t}_{\phi р 0,5 A}-$ часова характеристика фронту імпульсного сигналу; $\mathrm{t}_{3 \mathrm{p} 0,5 \mathrm{~A}}$ - часова характеристика зрізу імпульсного сигналу; $\mathrm{P}_{\mathrm{T}}, \mathrm{P}_{\mathrm{B}}$ - максимальні значення зрізаного розподілення

3 міток ( $A_{\text {імп.л }}$ та $\left.A_{\text {імп.п }}\right)$, які обчислюються на основі різниці максимальних значень зрізаного розподілення $\mathrm{P}_{\mathrm{T}}$ і $\mathrm{P}_{\mathrm{B}}$ [6]:

$$
A_{\text {імп. }}=\left|P_{T}-P_{B}\right|
$$

На основі амплітуди для кожної 3 міток обчислюється момент часу $t_{\phi p 0,5 A}$ та $t_{3 p 0,5 A}$ на

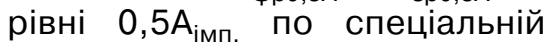
програмі обробки параметрів імпульсних сигналів та визначаються цифрові значення

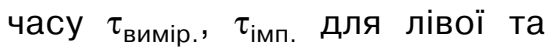
правої міток за формулами:

$$
\begin{gathered}
\tau_{\text {вимір. }}=\left(t_{\text {Фр0,5A}}-t_{\text {поч. }}\right) \Delta t \\
\tau_{\text {імп. }}=\left(t_{3 р 0,5 \mathrm{~A}}-t_{\phi р 0,5 \mathrm{~A}}\right) \Delta t,
\end{gathered}
$$

де $\Delta \mathrm{t}$ - шаг квантування імпульсного сигналу, $\mathrm{t}_{\text {поч. }}$ - момент часу видачі синхросигналу датчиком синхронізації для початку АЦП.

Допуск неузгодженості діагонального, поздовжнього та поперечного суміщення фарб складає 0,01 мм, тому час витрачений на проходження цього шляху $\left(\tau_{0,01} \mathrm{Mm}\right)$ необхідно враховувати на наступному етапі функціонування алгоритму при аналізі виміряних параметрів суміщення фарб.

На третьому етапі здійснюється аналіз визначених часових характеристик для кожної мітки $\left(\tau_{\text {імп.Л}}, \tau_{\text {імп.П }}, \tau_{\text {імп. }}==\tau_{\text {вимір.Л }}\right.$ $\left.=\tau_{\text {вимір.п }}\right)$ і визначення зміщення орієнтації аркуша перед його входженням до друкарської секції. Аналізуються умови :

1) $\tau_{\text {вимір.л }}-\tau_{\text {вимір.п }}>\tau_{0,01} \mathrm{MM}-$ діагональне зміщення лівого краю аркуша;

2) $\tau_{\text {вимір.п }}-\tau_{\text {вимір.л }}>\tau_{0,01} \mathrm{MM}-$ діагональне зміщення правого краю аркуша;

3) $\tau_{\text {імп. }}-\tau_{\text {імп.н }}>\tau_{0,01}$ мм поперечне зміщення аркуша вліво;

4) $\tau_{\text {імп.н }}-\tau_{\text {імп. }}>\tau_{0,01} \mathrm{MM}-$ поперечне зміщення аркуша вправо;

5) $\tau_{\text {вимір.П }}-\tau_{\text {вимір.н }}>\tau_{0,01}$ MM та $\tau_{\text {вимір.л }}-\tau_{\text {вимір.н }}>\tau_{0,01}$ MM поздовжнє зміщення аркуша проти напрямку руху.

Алгоритмічне забезпечення визначення параметрів суміщення фарб та напряму їх стабілізації 

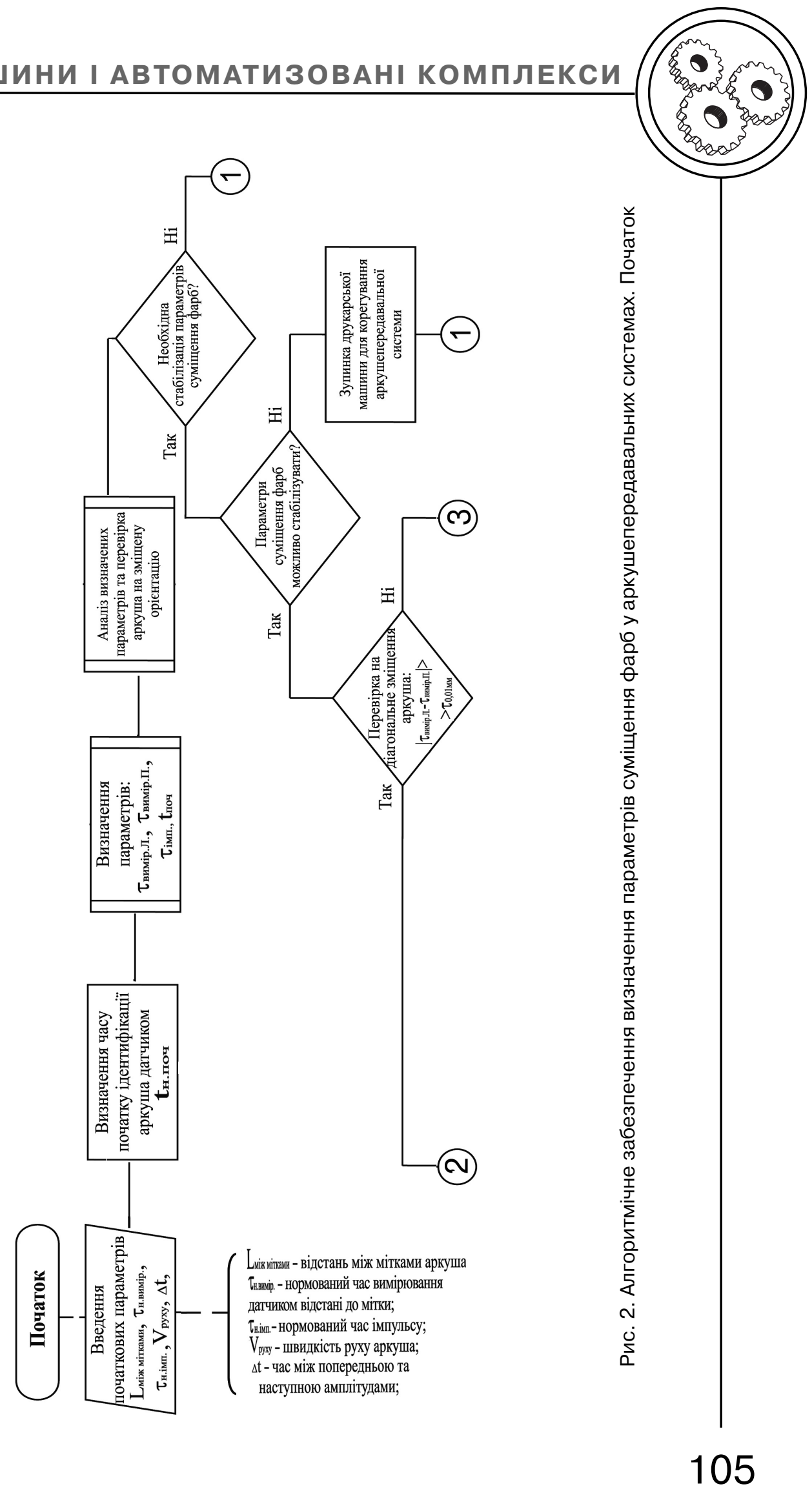


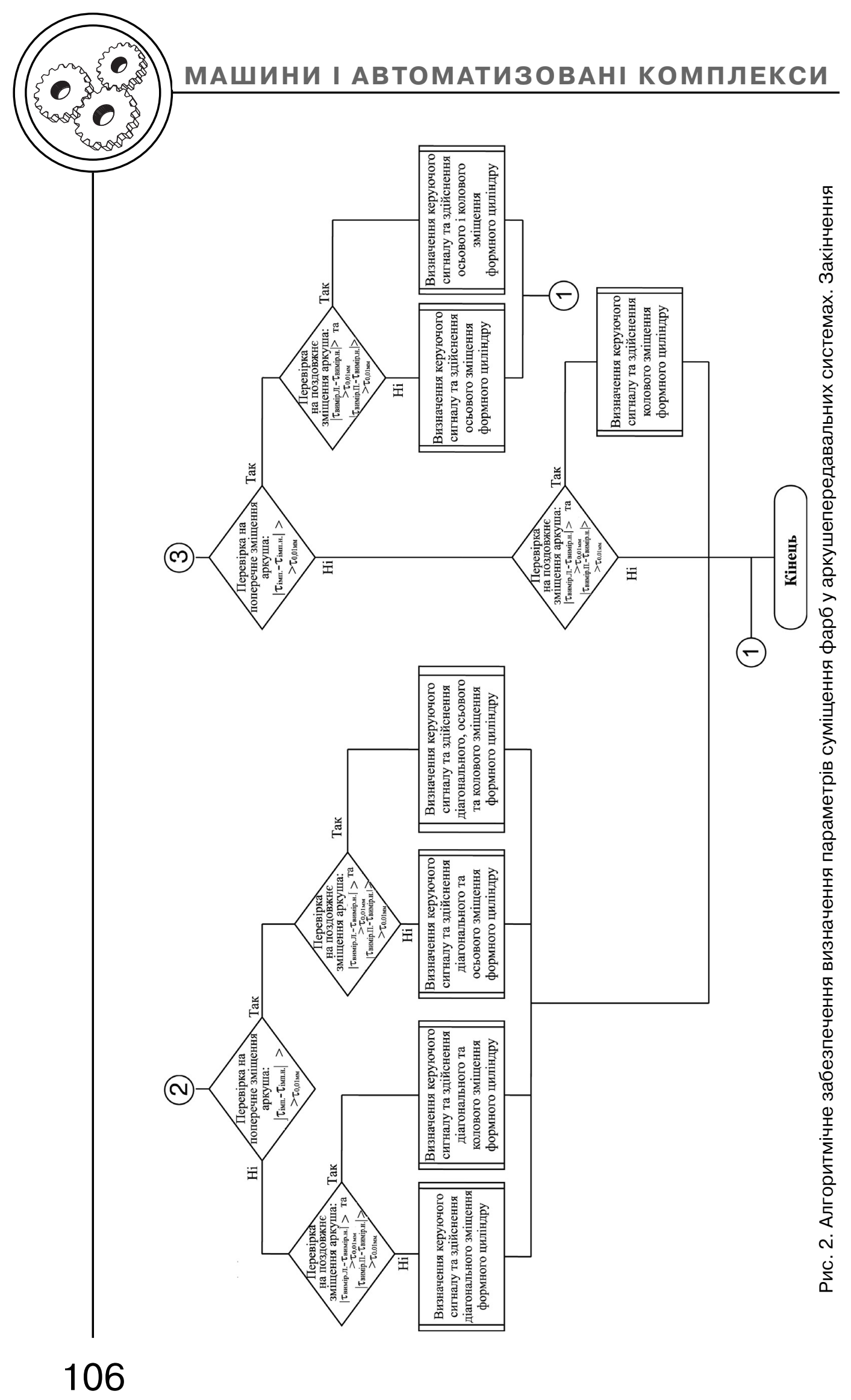


у аркушепередавальних системах представлений на рис. 2.

Алгоритм об'єктивного цифрового визначення параметрів суміщення фарб у аркушепередавальних системах на основі визначення часових характеристик імпульсних сигналів, які моделюють параметри орієнтації технологічних міток, забезпечує високу точність контролю положення аркуша, що визначає подальший напрям дослідження процесів стабілізації поперечного, поздовжнього та діагонального суміщення фарб.

\section{Висновки}

1. Алгоритм визначення параметрів суміщення фарб, з ви-

1. Дроздов В. Н. Автоматизация технологических процессов в полиграфии / В. Н. Дроздов. - М. : Изд-во МГУП, 2006. - 252 с. 2. Штоляков В. И. Печатные системы фирмы Heidelberg : Офсетные печатные машины / В. И. Штоляков, А. В. Федосеев, Л. И. Зирнзак, И. А. Егоров, С. П. Вартанян, Э. С. Артыков. - М. : Изд-во МГУП, 1999. - 216 с. 3. Мельников О. В. Технологія плоского офсетного друку : підручник за ред. Е. Т. Лазаренка / О. В. Мельников. - Львів : Афіша, 2003. - 383 с. 4. Чехман Я. І. Друкарське устаткування / Я. І. Чехман, В. Т. Сенкусь, В. П. Дідич., В. О. Босак. - Львів : УАД, 2005. - 466 с. 5. Морфлюк В. Ф. Засоби цифрового визначення та стабілізації паралельності переднього краю листа у листових друкарських машинах / В. Ф. Морфлюк // Технологія і техніка друкарства. Зб. наук. праць Видав.-поліграф. ін-т НТУУ «КПІ». - 2011. - № 3(33). - С. 35-40. 6. Морфлюк В. Ф. Цифрове визначення та стабілізація параметрів технологічних процесів у рулонних друкарських машинах / В. Ф. Морфлюк. - К. : ВПЦ «Київ. політехніка», 2008. - 164 с.

1. Drozdov V. N. Avtomatizacija tehnologicheskih processov $v$ poligrafii / V. N. Drozdov. - M. : Izd-vo MGUP, 2006. - 252 s. 2. Shtoljakov V. I. Pechatnye sistemy firmy Heidelberg : Ofsetnye pechatnye mashiny / V. I. Shtoljakov, A. V. Fedoseev, L. I. Zirnzak, I. A. Egorov, S. P. Vartanjan, Je. S. Artykov. - M. : Izd-vo MGUP, 1999. - 216 s. 3. Melnykov O. V. Tekhnolohiia ploskoho ofsetnoho druku : pidruchnyk za red. E. T. Lazarenka / O. V. Melnykov. - Lviv : Afisha, 2003. - 383 s. 4. Chekhman la. I. Drukarske ustatkuvannia / la. I. Chekhman, V. T. Senkus, V. P. Didych., V. O. Bosak. - Lviv : UAD, 2005. - 466 s. 5. Morfliuk V. F. Zasoby tsyfrovoho vyznachennia ta stabilizatsii paralelnosti perednoho kraiu lysta u lystovykh drukarskykh mashynakh / V. F. Morfliuk // Tekhnolohiia i tekhnika drukarstva. Zb. nauk. prats Vydav.-polihraf. in-t NTUU «KPI». - 2011. - № 3(33). - S. 35-40. 6. Morfliuk V. F. Tsyfrove vyznachennia ta stabilizatsiia parametriv tekhnolohichnykh protsesiv u rulonnykh drukarskykh mashynakh / V. F. Morfliuk. - K. : VPTs «Kyiv. politekhnika», 2008. - 164 s.

$$
\begin{array}{r}
\text { Рецензент - Ю. О. Шостачук, к.т.н., } \\
\text { доцент, НТУУ «КПІ» }
\end{array}
$$

EOM, дозволяє оптимізувати цесу друкування в аркушевих друкарських машинах внаслідок довільних зміщень орієнтації ар-
куша у аркушепередавальній системі.

2. Запропонований алгоритм визначає подальший настабілізації параметрів сумівальних системах на основі циімпового аналізу параметрів люють параметри суміщення фарб, у реальному масштабі часу.

Надійшла до редакції 20.12.13 